\title{
An Assessment of Household's Out of Pocket Healthcare Payment and Impoverishment in Nepal: Evidence from Nepal Living Standard Survey III
}

\author{
Arjun K Thapa \\ School of Development and Social Engineering \\ Pokhara University \\ Email: yogirajarjun@gmail.com
}

\begin{abstract}
Despite Government of Nepal's effort of universalizing basic free health care services and other demand side financing health schemes, there is an ongoing debate regarding equity in health service coverage, availability and high out of pocket payment. So this study intends to assess out of pocket payment and its associated factors and its implication on impoverishment. A cross sectional descriptive study was designed which is based on Nepal Living Standard Survey III 2010/11, a rich and well representative secondary data of Central Bureau of Statistics, National Planning Commission Nepal. The information about individuals who reported out of pocket healthcare payment was extracted from 28,747 individuals (or 7,020 households) of the survey. An individual from a household is considered as the unit of study. The major findings of the study show that age, caste ethnicity, place of residence, ecological belt and development region have statistically significant association with OOP payment. Due to OOP expenditure near about 3 percent of people are falling below the poverty line. The impoverishment rate is high among people residing in rural areas (3.4\%), Terai belt (3.4\%) and Eastern development region (3.7\%). Higher impoverishment level in Terai and Eastern development region where health facilities are fairly available in comparison to remote Mountain belt, low developed Far west and Mid-west only signifies low availability and utilization of health services. So there is a need to address lacunae in fair coverage and utilization of health services across the country along with impoverishment.
\end{abstract}

Keywords: Healthcare expenditure, impoverishment, out-of-pocket payment, poverty

\section{Introduction}

Ever since First and second Long Term Health policies were implemented during 1990's, the government of Nepal (GoN) was committed to expand the coverage of basic health care services across the country targeting the ultra-poor, poor, disadvantaged and marginal sections of people. Out-of-pocket payments (OOP), which refer to payments made by households at the point of receiving health services like hospital bills, doctors' consultation fees and purchases of medication
(WHO, 2006), is big hurdle towards universal health coverage (UHC). Despite fair increase in coverage by public health facilities, and awareness towards modern medicines the private payment made by individuals or households from their own pocket or out of pocket (OOP) spending has been on rise, impinging the poorer sections of people. OOP health expenditure for any household or individual is devastating if it exceeds her/ his ability to pay (ATP). According to Jack (1999) if an individual falls sick and wants

Journal of Development and Social Engineering

Volume 3 | Number 1 | December 2017, 17-25

ISSN 2382-5332 @ School of Development and Social Engineering, Pokhara University 
to purchase health care services, then he has to reallocate his expenditure among health care commodity and other market commodities in order to increase purchase of every additional healthcare service units. Now he may have to reduce his general consumption of other commodities. In many instances, people residing in developing and low income countries, where common people are not insured, may face adverse shocks. People sometime curtail their regular basic consumptions share, sell their assets or borrow in order to face such financial shocks arising in order to pay for their medical related expenses.

In many instances health care payment (OOP) may lead to impoverishment. Impoverishment occurs when people or households fall below the poverty line because of healthcare expenditure. Based on the study of 11 low to middle income Asian countries van Doorlaer et al. (2006b) estimated that poverty rates (US $\$ 1$ per day) would increase by 2.7 percentage points (or 78 million people) if household resources were assessed after accounting for health expenditures. Ghosh (2011), while measuring catastrophic health care expenditure incidence ( $00 \mathrm{P}>10$ percent consumption) of India, found that $4.4 \%$ of total population in India fell below poverty line because of OOP payment during 1993/94 to 2004/05 period.

In order to ascertain universal healthcare coverage and financial risk protection the GoN implemented Free Health Care Program(FHCP), promulgating basic healthcare as component of human rights in 2009 (Adhikari, 2013). The FHCP was targeted to ensure right to basic health care services to all Nepalese citizens; to increase coverage and utilization of health services by poor, disadvantaged and targeted groups (RTI, 2010).Most of the health policies and programs, especially the demand side financed programs aimed to reduce OOP and impoverishment. Even Nepal Health Sector Plan II (NHSP-2)'s vision was also aimed to improve the health and nutritional status of the Nepalese population, especially for the poor and excluded ones as well as to contribute to poverty reduction by providing equal opportunity for all to receive highquality and affordable health care services. (MoHP, 2010). But most of the studies show that households in low-income countries spend a significant portion of their resources (OOP) on remedial health care. For instance a study of public primary facilities, in seven districts across Nepal shows more than half of outpatient visitors pay from their pocket (OOP) for healthcare services where diagnosis and sufficient list of medicines are free (Thapa et al., 2016).It seems that mere provision of healthcare coverage, availability and freeing some medicines has not been able to cap up OOP spending especially by poorer, disadvantaged and marginalized section of the society leading to catastrophic health care payment causing impoverishment or tendency of households falling under the trap of poverty line.

So this study intends to describe the association of OOP payment with household characteristics, magnitude and distribution of OOP payments; and the incidence of poverty that occurs because of OOP payments in Nepal.

\section{Data and Methods}

This study is a cross-sectional analytical design, aimed to describe associational relationship between OOP and sociodemographic characteristics of households who are seeking health care service, and level of impoverishment due to OOP expenditure. The source of data is based on secondary raw data (NLSS III, 2010/11) of Central Bureau of statistics (CBS), National Planning commission / Government of Nepal which is latest till date and a nationally representative data. NLSS III, a national household survey conducted by CBS follows the World Bank's Living Standards Measurement Survey (LSMS) methodology. 
The study depends on cross sectional data extracted on demographic, consumption and health sections of NLSS III which comprised 7,020 households comprising around 28,000 individuals. But the population of interest for the study was only 5,518 individuals who reported being ill or injured within the last one month from the day of interview. The unit of analysis is household and individual. Cross tabs and multiple tables was used where comparison were required. For comparative study and causal relational studies chi square test was used as most of the attributes are of qualitative nature. It was analyzed using STATA package and MS Excel spread sheet.

\section{Estimation of Impoverishment or poverty:} Poverty impact of OOP is the difference between the average level of poverty before healthcare payments and that after payments (Wagstaff and Doorslaer 2003). As followed by Garg \& Karan (2008), our study follows pre-OOP (or pre-payment) poverty as the household's gross food consumption expenditure (NRs. 19,206) poverty line fixed by the Central Bureau of Statistics (CBS) / National Planning commission of Nepal. The pre-payment headcount poverty or Gross poverty headcount as formulated by O'Donnell, Wagstaff \& Doorslaer 2003; \& Lindelow, 2008; Gosh, 2010. The prepayment headcount poverty (pre-Hp) can be measured as:

$$
\text { pre } H p=\frac{1}{n} \sum 1\left(x_{i} \leq P L\right) \ldots \ldots . . . . . . . . .(1)
$$

Where, is per capita consumption expenditure (in NRs), PL is the poverty line (in NRs) and $\mathrm{n}$ is the number of individuals.

Similarly, the post-00P payment headcount poverty (post-Hp) is computed by deducting health care payments (measured by actual OOP payments for all households) from household's consumption expenditure and then comparing with the poverty line (PL):

$$
\text { post } H p=\frac{1}{n} \sum 1\left(x_{i}-O O P\right) \leq P L .
$$

Lastly to measure what percentage of non-poor fall below the poverty due to healthcare expenditure the pre-poverty rates are subtracted from post-poverty rates.

\section{Results and Discussion}

Out of total 5,518 reported to be sick or ill in the last one month from the day of interview but around $30 \%$ of them did not seek any treatment in formal sector. The out of pocket expenditure is the private healthcare expenditure spent by the households or individuals for their seeking healthcare services. Over 60 percent of the total population seeking healthcare services face out of pocket healthcare payment.

OOP by demographic characters: age, sex, caste ethnicity: Health as an augmenting commodity accumulates initially as one grows in age but it begins to decline after some point of age (old age). It is assumed that the younger and older population's tendency to seek health care services are likely to be high so eventually would lead to higher OOP health expenditure than other age groups. In the given table below OOP payment is highest among the population below 14 years and below combined. But as the OOP expenditure for older population is not that high as expected, the association is statistically significant $(\mathrm{P}<0.01)$. Statistically, there is no significant association between OOP and sex of the respondents. OOP is higher among Terai Madhes caste (91\%) and lowest among Janajatis (72\%). The association between caste ethnicity and OOP is statistically significant $(\mathrm{P}<0.01)$. OOP is higher among people residing in urban areas owing to easy availability of medical facilities than in rural areas and the association between OOP and place of residence is statistically significant $(\mathrm{P}<0.01)$. As per ethnicity OOP payment among Madhesi caste is highest (89 percent) whereas it is lowest in mountain belt. 
Table 1: OOP payment by Demographic and spatial characteristics

\begin{tabular}{|c|c|c|c|}
\hline Variable & Category & No OOP & OOP \\
\hline \multirow[t]{5}{*}{ Age*** } & $0-4(\mathrm{~N}=939)$ & 13.2 & 86.8 \\
\hline & $5-14(\mathrm{~N}=1274)$ & 20.7 & 79.3 \\
\hline & $15-44(\mathrm{~N}=2015)$ & 20.2 & 79.8 \\
\hline & $45-59(N=746)$ & 24.5 & 75.5 \\
\hline & 60 above $(\mathrm{N}=544)$ & 22.2 & 77.8 \\
\hline \multirow[t]{2}{*}{ Sex ${ }^{* * *}$} & male $(\mathrm{N}=2540)$ & 19.1 & 80.9 \\
\hline & female $(\mathrm{N}=2978)$ & 20.7 & 79.3 \\
\hline \multirow{4}{*}{ caste ethnicity*** } & Brahman/chhettri (N=1732) & 22.3 & 77.7 \\
\hline & Hill Janajatis(N=1557) & 27.9 & 72.1 \\
\hline & Tarai Madhesi \& other( $\mathrm{N}=1445)$ & 8.9 & 91.1 \\
\hline & All Dalits $(\mathrm{N}=784)$ & 19.3 & 80.7 \\
\hline \multirow[t]{2}{*}{ urban/rural $* * *$} & $\operatorname{urban}(\mathrm{N}=1587)$ & 13.8 & 86.2 \\
\hline & rural(N3931) & 22.4 & 77.6 \\
\hline \multirow[t]{3}{*}{ Ecological Belt*** } & mountain $(\mathrm{N}=360)$ & 29.7 & 70.3 \\
\hline & hill( $(N=2518)$ & 27.6 & 72.4 \\
\hline & terai $(\mathrm{N}=2640)$ & 11.3 & 88.8 \\
\hline \multirow[t]{5}{*}{ Development region $* * *$} & eastern $(N=1355)$ & 19.1 & 80.9 \\
\hline & centeral( $(\mathrm{N}=1934)$ & 15.3 & 84.7 \\
\hline & western( $(\mathrm{N}=1117)$ & 23 & 77 \\
\hline & mid-western(N=779) & 26.8 & 73.2 \\
\hline & far-western(N=333) & 24 & 76 \\
\hline
\end{tabular}

Source: Self compilation from NLSS III, 2010/11

The association between OOP and ecological belt is statistically significant $(\mathrm{P}<0.01)$. OOP payment is highest in Central Development region (84.7\%) then followed by Eastern region $(80.9 \%)$ to lowest in Midwestern region $(73.2 \%)$. Statistically the association between development region and OOP is significant $(\mathrm{P}<0.01)$.
Outofpocketpaymentandimpoverishment: OOP as percentage of total consumption expenditure is $3.33 \%$ whereas it is around $7 \%$ of non- food expenditure. As expected the share of OOP as percentage of consumption is higher among the bottom fifth but richest fifth's OOP as percentage of consumption is around 2 percent.

Table 2: OOP as share of consumption expenditure of $\mathrm{HH}$

\begin{tabular}{lcc}
\hline & $\begin{array}{c}\text { OOP as \% of Consumption } \\
\text { expenditure of } \mathbf{~ H H}\end{array}$ & $\begin{array}{c}\text { OOP as \% of non-food } \\
\text { expenditure }\end{array}$ \\
\hline poorest 20\% & 5.65 & 20.45 \\
2nd poorest 20\% & 5.26 & 18.18 \\
Middle & 4.45 & 12.86 \\
2nd richest 20\% & 3.86 & 9.55 \\
Richest 20\% & 1.96 & 3.22 \\
\hline Total & $\mathbf{3 . 3 3}$ & $\mathbf{7 . 0 7}$ \\
\hline
\end{tabular}

Source: Self compilation from NLSS III data, 2010/11 
But the OOP as percent of non- food expenditure is very high (20\%) among bottom fifth and second bottom fifth (18\%). The richest OOP share of non-food expenditure is only around 3 percent. This signifies bottom fifth's likelihood of facing catastrophic payment.

The incidence of poverty before OOP adjustment was around 31 percent during 2003/04 (NLSS II) but when household's consumption is adjusted for health care expenditure (OOP) then the level of impoverishment or level of poverty due expenditure to cope episode of illness rises by 1.5 percentage point or actual (Post OOP) incidence of poverty would be $32.1 \%$. Similarly, as per NLSS III the poverty rate (pre 00P) is $24.7 \%$ but it increases to 27.6 percent after adjustment for OOP health care expenditure on household's consumption basket. It indicates that due to health care expenditure around 2 percent of the population is falling under the poverty line.

Moreover the rate of impoverishment or people falling under the poverty line is 1.5 percentage point to 2.9 percentage point signifies an increasing trend. Similarly the table below shows the level of impoverishment based on place of residence, ecological belt and development region.

The given table shows pre OOP and post OOP poverty. By subtracting pre OOP $\%$ column from the post OOP \% column we derive last column or impoverishment column. The positive percentage points shows increase in level of poverty or impoverishment. Similarly there is significant increment in impoverishment by ecological belts. The impoverishment is significantly (3.4\% increment) higher due to OOP health expenditure. But it is surprising that impoverishment rate is highest $(3.4 \%)$ in Terai among the ecological belt. By development region impoverishment rate is highest in Eastern development region (3.7\% point), then followed by Western $(3.1 \%$ point) and Mid-western (3\% point) regions.

Table 3: change in incidence of poverty due to health expenditure

\begin{tabular}{|c|c|c|c|}
\hline \multirow[t]{2}{*}{ NLSSIII } & \multirow{2}{*}{$\begin{array}{c}\text { Pre-00P poverty } \\
\%(\mathrm{~N}=7083)\end{array}$} & \multicolumn{2}{|c|}{ Post 00P poverty } \\
\hline & & $\%(\mathrm{~N}=7917)$ & Impact \\
\hline \multicolumn{4}{|c|}{ Place of residence } \\
\hline urban & 8.3 & 10.3 & 2 \\
\hline rural & 32.4 & 35.8 & 3.4 \\
\hline \multicolumn{4}{|l|}{ Belt } \\
\hline Mountain & 20.3 & 23.1 & 2.8 \\
\hline Hill & 22.2 & 24.7 & 2.5 \\
\hline Terai & 28.3 & 31.7 & 3.4 \\
\hline \multicolumn{4}{|l|}{ Dev. Region } \\
\hline Eastern & 20.2 & 23.9 & 3.7 \\
\hline Central & 16.7 & 19.3 & 2.6 \\
\hline Western & 26.3 & 29.4 & 3.1 \\
\hline Mid-Western & 33.6 & 36.6 & 3 \\
\hline Far-Western & 50.5 & 52.5 & 2 \\
\hline Total & 24.7 & 27.6 & 2.9 \\
\hline
\end{tabular}


The concentration curve shown in the figure has two components: the Lorenz curve-indicating OOP concentration curveproportion of OOP burden on respective proportion of population by income quintile.

It is evident from the figure that OOP concentration curve is bulging out above from equality diagonal. It means OOP burden with respect to proportion of population is more among lower quintile segment of population of Nepal. It means higher healthcare burden (OOP) is shouldered by low-income quintile segments of people. The Lorenz is bulging out above more showing higher disparity in terms of shouldering healthcare burden.

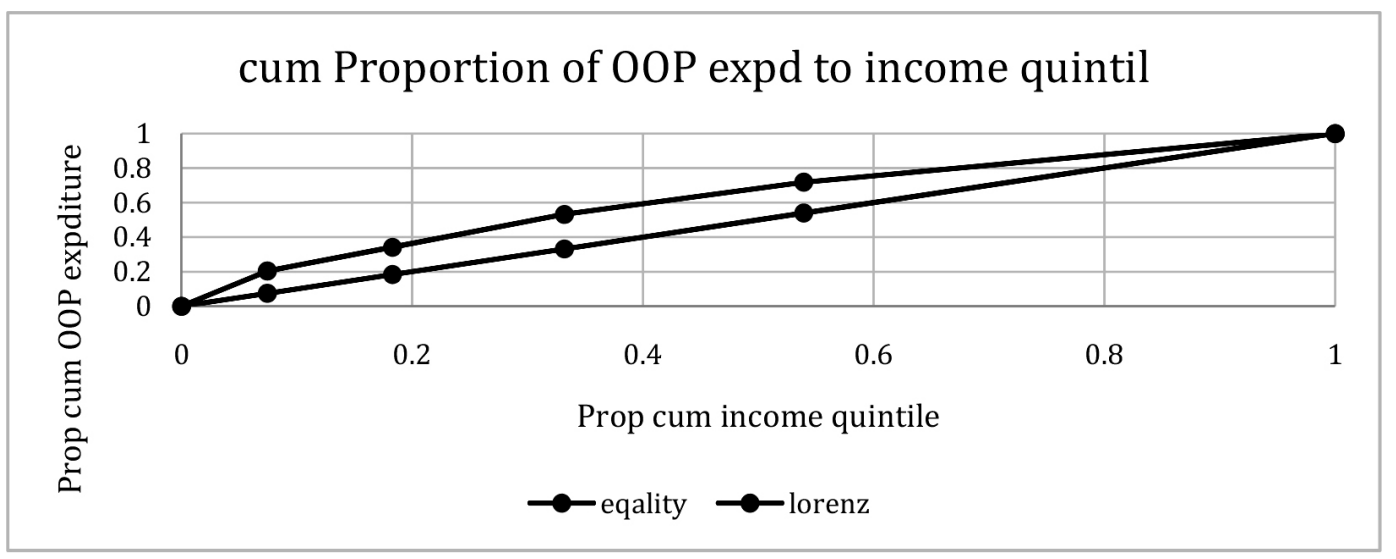

Figure 1: 00P concentration curve

Source: Self compilation from NLSS III data

In this study age, caste ethnicity, place of residence, ecological belt and development region have statistically significant association with OOP payment but the association of gender is not significant. OOP payment is higher among: younger (< 14 years age), Terai belt residents (89\%), Madhesi community (91\%), urbanites, and central development region. Country wide OOP payment of Nepal as percentage of total consumption expenditure is $3.33 \%$. This finding is similar to study of poorer Indian states of Assam and Bihar (3.8\% and 2\% respectively) even though India's overall OOP payment as percent of consumption is around 5 percent (Garg \& Karan, 2009). But current findings are in contrast to another similar study of Nepal (Gupta \& Chowdhury, 2014), which may be due to methodological differences. This study shows that the share of OOP as $\%$ of average consumption for poorest quintile and second poorest quintile is highest (around 5 percent) in comparison to richest fifth of the population (around
2 percent). It coincides with the study done on implications of FHCP of Nepal that concluded its unintended effect on marginal and targeted population whose 00P payment tendency and catastrophic payment did not improve (Adhikari, 2013). But some other studies conducted in slums of Hyderabad, India and in Western Kenya found much higher 00P as \% of household expenditure i.e. $10 \%$ and $8 \%$ respectively (Banerjee et al., 2009). Further the OOP as \% of nonfood expenditure is highest (around 20\%) for poorest fifth. It signals about significant number of households facing catastrophic health care payment if we mark households health expenditure at $40 \%$ of non-food consumption cut off line. Comparing the incidence of pre and post health expenditure adjustment during 2003/04 and 2010/11 shows an increase in poverty by around 2.9 percent. The findings are similar to the study done in India Peters et al (2003).

Moreover after adjustment of OOP payment there is significant increase in 
incidence of poverty among people residing in rural areas, Terai belt and people of Eastern development region by $3.4 \%, 3.4 \%$ and $3.7 \%$ respectively. It indicates disparity in health coverage and affordability. Lower percentage of impoverishment in Hill region (2.5\%) and low developed Far Western region (2\%) does not mean a better off condition but it may indicate low utilization of health services due to unavailability of health facilities, and eventually leading to low OOP and low impoverishment. A study done in Bihar and Assam, the poorer Indian states also show low 00P percent share of consumption which was due to low utilization of facilities (Thapa \& Adhikari, 2016). The above arguments are also supported by findings another study on Nepal's healthcare system in 2004which infers that distribution of financial protection and access to health in rural and remote areas did not improve much (Adhikari \& Maskay, 2004).

Even though the Lorenz curve is highly skewed away from equality diagonal showing higher consumption disparity among the poor and richer quintiles but the concentration curve shows that rich pay higher proportion of total health expenditure than poor as the OOP curve is bulging out initially but is equating with equality curve for richer quintile of the population later. This study is similar to the findings of other studies (Mahal 2003; Mahal et al., 2001). Despite afore mentioned facts that richer paying higher proportion of private OOP payment for health care services but some studies found that a third of the population reporting illness do not seek any health care services (Thapa \& Adhikari 2016). There are many reasons for avoiding health seeking but lack of ability to pay, remoteness (indirect cost) and unavailability of health facilities and medicines, and rising health care cost dearly affect healthcare utilization.

\section{Conclusion}

Out of pocket payment is associated with age, caste ethnicity, place of residence, belt and development region. Due to OOP payment just over three percent of the population fall below the poverty line, is on an increasing trend. Apart from rural area, the higher incidence of impoverishment in Terai and Eastern development region where health facilities are fairly available in comparison to remote Mountain belt, low developed Far west and Mid-west only signifies low availability and utilization of health services. So there is a need to address lacunae in fair coverage and utilization of health services across the country along with impoverishment of commons.

\section{Acknowledgements}

I would like to acknowledge Dr. Shiva Raj Adhikari, Associate Professor, Department of Economics, Patan Multiple Campus, Tribhuvan Universty, for his valuable guidance and support.

\section{References}

Adhikari, SR. \& Maskay, N.M.(2004). Health sector policy in the first decade of Nepal's Multiparty democracy. Does clear enunciation of health priorities matter? ELSEVIER, Health Policy 68; 103-112.

Adhikari, SR. (2013).'Choices of health care financing schemes for resource poor country: An analysis of Nepal's experiences'. Health 5 (2013) 1295-1302.

Adhikari S.R. (2013). An evaluation of Nepal's free health care scheme: evidence from a quasi-experimental design. In: Social Science Research Network.

Banerjee, A., Esther, Du. O, Glennerster, R., \& Kinnan, C. (2009). The Miracle of Microfinance? Evidence from a Randomized Evaluation, mimeo, MIT, 2009.

Dupas, P. (2011).'Health Behavior in Developing Countries'. Annual Review of Economics, Vol. 3 (Sep. 2011).

Garg C. and Karan, A.K. (2009).'Reducing out of-pocket expenditures to reduce poverty: a disaggregated analysis at rural-urban and state level in India', 
Health Policy and Planning;24:116-128.

Ghosh, S. (2011). Catastrophic Payments and Impoverishment due to Out-ofPocket Health Spending. Economic \& Political Weekly.EPW. November 19, 2011, vol xlvi no 47 http://www. indiaenvironmentportal.org.in/files/ file / Out-of-Pocket $\% 20$ Health $\% 20$ Spending.pdf

Gupta, I. \& Chowdhury, S. (2014). Correlates of out-of-pocket spending on health in Nepal: implications for policy. WHO South-East Asia Journal of Public Health; July-December 2014, 3 (3-4).

Jack, W. (1999). Principles of health economics for developing countries. Washington DC: The World Bank.

Lindelow, M. (2003). The utilization of curative health care in Mozambique: Does Income Matter? The World Bank. Center for study of African Economics. Oxford University Press.

Mahal A, Singh J, Afridi F et al.(2001). Who benefits from public health spending in India? New Delhi: National Council of Applie Economic Research.

Mahal A.(2003). The distribution of public health subsidy in India. In: Yazbeck AS, Peters $D H$ (eds). Health policy research in South Asia: building capacity for reform. Human Development Network, Health, Nutrition and Population series. Washington DC: The World Bank, pp. 33-63, 2003.

MoHP.(2010).Nepal Health Sector Programme- Implementation Plan II (NHSSP-IP 2) 2010 - 2015. Kathmandu: Ministry of Health and Population / Government of Nepal.
Thapa, A.K., Ghimire, N. \& Adhikari, SR. (2016). 'Access to Drugs and Out of Pocket Expenditure in Primary Health Facilities'. Journal of Nepal Health Research CouncilSep-Dec;14(34):139-42.

Thapa, A.K. \& Adhikari, S.R. (2016). 'Characteristics of Morbidity and Choice of Health Care Facilities in Nepal'. Journal of Advanced Academic Research (JAAR), July Vol. 2.No. II.

Peters DH, Rao SK, Fryatt R. (2003).'Lumping and splitting: the health policy agenda in India'. Health Policy and Planning 18: 249-60.

RTI International.(2010).Health System Performance. Research Triangle Park, NC, USA.

Van Doorslaer E, O. O'Donnell, R. P. RannanEliya, A. Somanathan, S. R. Adhikari,C. C. Garg, D. Harbianto, A. N. Herrin, M. N. Huq, S. Ibragimova, A. Karan, C. W. Ng, B. R. Pande, R. Racelis, S. Tao, K. Tin, K. Tisayaticom, L. Trisnantoro, C. Vasavid, and Y. Zhao (2006b). 'Effect of payments for health care on poverty estimates in 11 countries in Asia: an analysis of household survey data', Lancet 368:135764.

Wagstaff, A., \& Van Doorslaer, E. (1992). Equity in the finance of health care: some international comparisons. Journal of health economics, 11 (4), 361-387.

Wagstaff, A., \& van Doorslaer, E. (2003). Catastrophe and impoverishment in paying for health care: with applications to Vietnam 1993-98. Health Economics, 12, 921-934. 